\title{
O PRINCÍPIO DA FRATERNIDADE NA PERSPECTIVA CRÍTICA: A PANDEMIA DA COVID-19 E A MITIGAÇÃO DO INDIVIDUALISMO
}

\author{
Rene José Keller ${ }^{1}$ \\ Vanessa de Oliveira Caetano ${ }^{2}$
}

DOI: https://doi.org/10.47306/978-65-88213-03-2.122-132

Sumário: 1 Introdução; 2 O princípio da fraternidade na perspectiva da teoria social crítica; 3 A fraternidade e a Covid-19: o que restará no contexto pós-pandemia? 4 Considerações finais; Referências.

\section{Introdução}

A fraternidade constitui o princípio da Revolução Francesa (1789) que menos alcançou notoriedade, visto que o correlato desenvolvimento do modo de produção capitalista findou por despontar a contradição entre liberdade e igualdade. No ideário comum, enquanto o bloco dos países socialistas, encabeçado pela extinta União Soviética (1922-1991), propugnava o princípio da igualdade, os países capitalistas ocidentais traziam a defesa da liberdade. A fraternidade teve o trágico destino de ser relegada a plano secundário, pois não denotava nenhum dos polos da contradição de mobilizou o século $\mathrm{XX}$.

Ainda que se fale em pós-modernidade, ou modernidade reflexiva, o estágio atual de desenvolvimento do pensamento político ainda está ancorado, de modo rígido, nos ideais que nortearam a Revolução Francesa. As perspectivas que orientam o postulado da fraternidade não raro estão associadas à doutrina social da Igreja. Isso não significa, todavia, que não possa ser objeto de estudo da teoria crítica, na vertente do marxismo, como é o caso do presente estudo.

A repetitividade ínsita ao cotidiano foi rompida com a eclosão da pandemia da Covid19, a qual demanda o abandono do individualismo à sua superação. Até o presente momento, ainda não se pode aferir com precisão em que medida a quebra de normalidade irá fixar novos modos de vida, de toda sorte, o presente artigo tem como objetivo examinar como a pandemia da Covid-19 pode mitigar o individualismo, que é o signo da racionalidade neoliberal vigente.

\footnotetext{
${ }^{1}$ Doutor em Direito, na linha de teoria e filosofia do Direito, pela Universidade do Estado do Rio de Janeiro (UERJ). Doutor em Serviço Social pela Pontifícia Universidade Católica do Rio Grande do Sul (PUCRS). Bacharel e Mestre em Ciências Jurídicas e Sociais. Advogado. E-mail: rene.j.keller@gmail.com.

${ }^{2}$ Especialista em Direito do Trabalho e Processual do Trabalho pela Fundação Escola Superior do Ministério Público (FMP/FEMARGS). Bacharel em Ciências Jurídicas e Sociais pela Pontifícia Universidade Católica do Rio Grande do Sul (PUCRS). Advogada. E-mail: adv.vanessacaetano@gmail.com.
} 
A título organizacional, o estudo foi dividido em duas partes, sendo que a primeira delas aborda o princípio da fraternidade sob o viés da teoria crítica. Ao contrário do que pode ser suposto, não se trata de infirmar a sua relevância, senão de sustentar que conforma um dos postulados da perspectiva crítica, no entanto, em constante duelo com a noção de liberdade individualista que se estabelece nos marcos do capitalismo. A segunda parte, ao seu turno, enfoca na pandemia provocada pela COVID-19, seus reflexos na rotina cotidiana, bem como nas possibilidades de enfrentamento ao individualismo e promoção da fraternidade de modo concreto.

Em relação à metodologia, este trabalho tem caráter de pesquisa qualitativa, envolvendo o raciocínio indutivo e dedutivo, tendo perfil interdisciplinar, articulando as áreas do Direito, da Filosofia, da Sociologia e da Economia Política. O campo epistêmico e o marco teórico são os da teoria crítica da sociedade capitalista (HORKHEIMER, 1991) e do Direito (LYRA FILHO, 2000). As fontes de pesquisa consistem em livros, artigos e documentos, analisados mediante as técnicas de revisão bibliográfica e análise documental.

\section{0 princípio da fraternidade na perspectiva da teoria social crítica}

A fraternidade não integraria o vocabulário político do nosso tempo, ainda que em condição menor em relação à liberdade e à igualdade, se não tivesse sido marcada pelo principal evento disruptivo da modernidade: a Revolução Francesa. Distantes no tempo e espaço, Eric Hobsbawn (2017, p. 106) e Friedrich Hegel (1999, p. 365) anuem, cada um ao seu modo, que a revolução foi obra dos filósofos que a inspiraram. Enquanto o primeiro, fiel ao materialismo, situa burguesia como classe impulsionadora deste processo, o segundo a encarou como afirmação do seu idealismo, resultante do progresso do espírito.

Se a Revolução foi obra dos filósofos, estes igualmente foram profundamente influenciados por ela. Como lembra Marcuse (1978, p. 17), o "idealismo alemão foi considerado a teoria da Revolução Francesa”, engajando tanto Hegel como seus pares idealistas (Kant, Fitche, Schelling) em elaborar sistemas filosóficos que incorporassem as bases racionais e os respectivos princípios emergentes. Em Hegel (1999, p. 25), a "história universal é o progresso na consciência da liberdade". A associação do movimento da história como progresso da liberdade permite que se afirme com acuidade que "Hegel é o filósofo da liberdade. Seu sistema trata de sua fundamentação e de suas principais determinações” (WEBER, 2013, p. 89). 
Se o idealismo alemão de Hegel se caracterizava pelo primado da liberdade, o discípulo assumido deste ${ }^{3}$, Karl Marx, ficou notabilizado como radical defensor da igualdade. Isso não significa que Marx pressupôs que todos os indivíduos são iguais, em aptidões e necessidades, pelo contrário, a máxima defendida, ultrapassando o horizonte estreito do direito burguês, era "De cada um segundo as suas capacidades, a cada um segundo as suas necessidades". (MARX,1985, p. 17).

O marxismo, a exemplo do princípio da fraternidade, é herdeiro dos postulados principiológicos da Revolução Francesa. Como matriz teórica do pensamento, não é antagônico às noções de liberdade, fraternidade e igualdade. Pelo contrário, a crítica é direcionada justamente na limitação que tais princípios têm de se efetivarem na sociabilidade capitalista. A liberdade não pode ser exercida plenamente, visto que uma das classes, a trabalhadora, no mais das vezes não dispõe dos meios necessários para a sobrevivência, sendo obrigada a vender a sua força de trabalho ${ }^{4}$ como meio de manutenção de existência, a um preço abaixo do mínimo necessário para prover condições dignas.

O jovem Marx, inclusive, denunciava a completa ausência de fraternidade no próprio conceito de liberdade, tal qual formulada na Declaração dos Direitos do Homem e do Cidadão, pois levava em consideração os interesses individualistas do burguês. Para Marx (2010, p. 49): “o direito humano à liberdade não se baseia na vinculação do homem com os demais homens, mas, ao contrário, na separação entre um homem e outro. Trata-se do direito a essa separação, o direito do indivíduo limitado, limitado a si mesmo". Por isso, Marx (2010, p. 49) completa "Ela [a propriedade] faz com que cada homem veja no outro homem, não a realização, mas, ao contrário, a restrição de sua liberdade".

A igualdade sofre crítica à medida que se restringe ao tratamento perante a lei, cuja equalização no plano jurídico não é capaz para mitigar a desigualdade material. Não se trata de sustentar a ideia de que todos devem acessar o mesmo produto social, no entanto, tampouco se pode anuir com a assertiva de que poucos concentrem a riqueza que é produzida socialmente, de modo que a igualdade seja meramente formal. Como refere Enzo Bello:

Dessa forma, revela-se falsa a igualdade entre os homens alegadamente instituída através da cidadania - existente só no plano formal da lei -, pois, por mais universais e efetivos que sejam os direitos constitucionais, não rompem com a exploração da força de trabalho que gera as desigualdades socioeconômicas e a pobreza

\footnotetext{
${ }^{3}$ Acerca da sua relação com Hegel, lembramos os dizeres do posfácio da segunda edição de "O Capital", de 1873: "[...] declarei-me publicamente como discípulo daquele grande pensador e, no capítulo sobre a teoria do valor, cheguei até a coquetear aqui e ali com seus modos peculiares de expressão". (MARX, 2014, p. 91).

4 "Por força de trabalho ou capacidade de trabalho entendemos o complexo das capacidades físicas e mentais que existem na corporeidade, na personalidade viva de um homem e que ele põe em movimento sempre que produz valores de uso de qualquer tipo" (MARX, 2014, p. 242).
} 
generalizada, típicas do sistema capitalista de produção e organização social. (BELLO, 2013, p. 153).

A fraternidade finda por ser elevada a um alto grau de abstração quando a organização social que reproduz o modo de vida, o capitalismo, pressupõe uma contradição na sua gênese: a oposição de classes. Isso não resulta, necessariamente, que as classes não tenham interesse comum na elevação do grau de bem-estar social, no entanto, no caso do Brasil significa a perpetuação de uma estrutura de desigualdade. É possível objetar que é justamente a falta da fraternidade que produza um cenário com tamanho abismo social. A assertiva poderia ser convalidada caso conformasse, de fato, uma ideologia dominante.

A racionalidade que orienta o tempo presente é a neoliberal, a qual modelou, a partir da “cultura da empresa", uma nova subjetividade específica aos desafios do tempo histórico. Demanda uma corporeidade que governe a si com base numa racionalidade competitiva, em que "deve maximizar os seus resultados, expondo-se a riscos e assumindo a inteira responsabilidade por eventuais fracassos" (DARDOT; LAVAL, 2016, p. 328). O neoliberalismo, portanto, não se resume a uma plataforma econômica gerida pelo plano político, visto que exige a formatação de uma individualidade compatível.

Esse individualismo balizado pela racionalidade neoliberal tem corroborado à mitigação da fraternidade, tendo em vista que a existência passa a ser preenchida pelos signos da competição, maximização dos ganhos e perdas individuais, meritocracia como produto do autoempenho. É lícito questionar, portanto: trata-se da fraternidade um princípio esquecido, como problema formulado na obra organizada por Antonio Maria Baggio (2008)? A resposta para a indagação pode ser localizada em Marx, que chegou a examinar, posto que brevemente, o motivo de a fraternidade ter sido deixada para trás em relação à igualdade e a liberdade. Segundo Marx (1848), “A fraternidade durou precisamente enquanto o interesse da burguesia encontrou-se fraternizado com o interesse do proletariado". Uma vez cumprido o desiderato de unificar o terceiro Estado para derrogar a antiga ordem, a fraternidade se tornou prescindível. Uma vez sedimentada a dominação de uma classe, o dito princípio pôde ser esquecido.

O esquecimento não se trata de um acidente da história, um lapso, senão o distanciamento do conceito com a respectiva e necessária base material. As forças sociais que conferem sentido aos conceitos, passado o conturbado período revolucionário, remodelaram os termos da contradição, que deixa de ser entre os defensores do antigo regime e o terceiro estado, senão da burguesia contra as classes subalternas, que não acessaram as mesmas benesses que os burgueses. A fraternidade foi rompida pela própria classe que defendia o postulado, quando da necessidade de divisar os seus interesses dos interesses da classe trabalhadora. 
Segundo a crítica de Giuseppe Tosi (2018, p. 399) "Um marxista definiria a fraternidade como um conceito que camufla e esconde as divisões irredutíveis entre as classes antagônicas; portanto seria, na melhor das hipóteses, uma ilusão". Inexiste em Marx uma fundamentação detida acerca da fraternidade, todavia, Axel Honneth (2017, p. 35) precisamente aponta que Marx enxergava uma contradição entre a liberdade no capitalismo e a concretização da fraternidade:

[...] o exercício de uma tal liberdade sob as condições de produção capitalistas está associado ao pressuposto de que o outro constitui apenas o meio para atingir os interesses do próprio, violando, assim, o princípio, já institucionalizado, da fraternidade. É para resolver essa contradição interna que Marx esboça o modelo de uma sociedade na qual a liberdade e a solidariedade estejam interligadas. (HONNETH, 2017, p. 35).

Isso não significa que o marxismo rechace os preceitos fundamentais da Revolução Francesa. Pelo contrário, Marx e a tradição crítica do marxismo são tributários direto de tais valores, no entanto, não pretendiam que fossem restritos a uma parcela da sociedade ou denotasse apenas uma ideia. A pretensão é levar às últimas consequências tais ideais, imprimindo-lhes vida material, concreta, considerando que tais preceitos não cabem na estreiteza individual da sociabilidade capitalista.

O curso da história foi abalado nesse ano de 2020 em razão da pandemia da Covid-19, que obrigou o governo e a população a quebrar a rotina cotidiana de normalidade, diante do necessário distanciamento social. Os modos de vida foram subitamente alterados, atendendo a recomendações médicas, inclusive com cerceamento de parte da liberdade individual (locomoção) e exercício profissional. A questão que se coloca é: os imperativos de esforços coletivos, demandando maior fraternidade, serão duradouros no cenário pós-pandemia? O que restará desses dias de alteração da normalidade? O individualismo esgarçado será restaurado?

\section{A fraternidade e a Covid-19: o que restará no contexto pós-pandemia?}

Em 2020, a pandemia provocada pelo novo coronavírus (COVID-19) obrigou o mundo a parar ou, ao menos, diminuir drasticamente o ritmo de produção, atingindo inclusive as liberdades individuais, dentre as quais, a de locomoção. Diante da rápida propagação do vírus, aliada a ausência de imunidade da população global, a recomendação da Organização Mundial da Saúde (OMS) para conter o avanço e para reduzir as perdas humanas, até o momento, é o "distanciamento" social; cuja expressão deve ter sido criada como eufemismo ao confinamento (AGAMBEN, 2020). Tal medida modificou drasticamente o cotidiano de parte considerável da população, visto que foi obrigada a abandonar as relações face a face presenciais. 
Em que pese o baixo índice de mortalidade no Brasil (4,3\%, em junho de 2020), a propagação acelerada do vírus atinge a milhões de pessoas em diversas partes do mundo e em curto espaço de tempo. O efeito da pandemia pode levar ao colapso diversos sistemas de saúde que não estavam equipados para enfrentar uma pandemia, e, no caso do Brasil, agravada pela ausência de políticas públicas e de investimentos no setor de saúde, de testes suficientes e eficazes o bastante para o diagnóstico preciso. Além disso, há a limitação de recursos humanos e equipamentos hospitalares para atender a todos os pacientes atingidos pela doença, principalmente, nos casos mais graves em que há necessidade de internação hospitalar com uso de respiradores mecânicos, bem como outras enfermidades paralelas e não relacionadas ao COVID-19 que demandam por atendimento médico.

Para evitar o contágio, algumas medidas básicas de conduta são recomendadas pelas autoridades científicas aos indivíduos, tais como, o uso de máscaras, a correta e frequente higienização das mãos com água corrente e sabão ou o uso de álcool gel 70\%, evitar aglomerações humanas, a manutenção de uma distância mínima de um metro entre os indivíduos e a permanência em casa até que haja o controle dos níveis de contágio (quarentena). Principalmente, no caso de suspeita de contaminação em que não haja sintomas graves. De acordo com o site da Organização Pan-Americana da Saúde (OPAS, 2020), a Organização Mundial da Saúde (OMS) declarou, em 30 de janeiro de 2020, que o surto da doença provocada pelo novo coronavírus (COVID-19) constitui uma Emergência de Saúde Pública de Importância Internacional e em 11 de março de 2020 a COVID-19 foi caracterizada como uma pandemia.

O Brasil é o atual epicentro da doença e em 25 de junho de 2020 foram confirmados pela OMS, oficialmente, 1.231.356 casos de contaminação e mais de 55.000 mortos, incluídos os novos casos da doença (OMS, 2020). Uma das principais causas do aumento do número de casos no país são atribuídas às medidas de relaxamento do isolamento social pelo governo federal e pela ausência de medidas político-econômicas que garantam uma renda mínima emergencial duradoura e a manutenção de vínculos empregatícios durante a pandemia, por exemplo.

No início da pandemia, o desconhecimento a respeito da doença e as determinações dos governos no âmbito estadual e municipal para fechamento do comércio em geral, bem como a manutenção apenas de atividades consideradas essenciais com diversas restrições, levaram a uma exacerbação do individualismo no país, constatado através de uma histeria coletiva para realização de estoques de álcool gel, aquisição de máscaras cirúrgicas em grandes quantidades, alguns materiais de higiene e alimentos, criando uma crise de abastecimento de farmácias e supermercados. 
O aumento abrupto no preço do álcool gel e das máscaras despertou a discussão presente na obra de Michael Sandel (2017), ao examinar o aumento extorsivo no preço de diversos serviços após um furacão que devastou a Flórida em 2004. Como refere na obra, não se trata de examinar o comportado individualista de indivíduos, pois diz respeito ao modo pelo qual a sociedade deve ser organizar, logo, são questões sobre justiça. Na condição de crítico do liberalismo, seguindo os traços de Aristóteles, Sandel (2017, p. 17) defende que "a ganância predadora da miséria humana, no nosso entender, deveria ser punida".

Os comportamentos dos agentes do mercado que encontram na tragédia um flanco aberto para o lucro fácil, opõem-se à noção de fraternidade ${ }^{5}$ e revelam o comportamento autocentrado e primitivo de determinados indivíduos, indiferentes à sorte de outros seres humanos, pois o que importa é garantir a própria sobrevivência. Esses indivíduos não se identificam como parte de um grupo e abdicam do seu papel como ser social e com responsabilidade coletiva. Tais condutas individualistas refletem no âmbito coletivo em diversos aspectos e evidenciam ainda mais as desigualdades sociais na sociedade brasileira.

O indivíduo que decide proteger a si mesmo garantindo o seu estoque pensa apenas na sua autopreservação e sobrevivência diante de um mal ainda muito desconhecido. Mas ao assim agir, contribui para a maior propagação do vírus, ao eliminar o direito do outro de adquirir o material necessário e em quantidade suficiente para adotar as mesmas recomendações básicas de proteção e segurança. Também acentua a desigualdade material, na medida em que o indivíduo que não possui condições econômicas não poderia sequer ter a oportunidade de realizar o seu estoque pela necessidade de escolha entre a proteção (álcool gel e máscara) e o alimento para sobreviver, atingindo, dessa forma, a liberdade individual.

Outro aspecto que acentuam as desigualdades e liberdades materiais é que os pobres enfrentam maiores obstáculos para manterem o distanciamento e o isolamento social, seja pelo número de membros da família que habitam um pequeno espaço de suas moradias, aumentando as chances de contágio, seja pela necessidade desses grupos familiares de permanecerem trabalhando e se deslocando por transporte público, em geral, tornando essas pessoas ainda mais vulneráveis à contaminação pelo vírus. Outra dificuldade fundamental enfrentada por esse grupo social são as deficiências de sistemas de saneamento básico e abastecimento de água

\footnotetext{
5 Conforme Daniela Ropelato (2008, p. 88), a ideia política da fraternidade universal é entendida "como conjugação de relações de pertencimento mútuo e de responsabilidade, como princípio de reconhecimento da identidade e do caráter unitário do corpo social, respeitando cada uma das diferentes multiplicidades".
} 
encanada, obstaculizando as medidas de higienização necessárias para reduzir as possibilidades de contaminação.

Como aponta Slavoj Žižek (2020), além da pandemia em si, houve a propagação do surto de vírus ideológicos, que estava em estado adormecido, como as fake news, teorias da conspiração paranoicas e os casos de racismo (Estados Unidos). Ainda, não se pode supor que a abdicação do convívio social tenha como mote uma fraternidade, senão o risco de perecimento da própria pessoa. De toda sorte, seja por qual motivo for, nem todos obedeciam aos ditames de distanciamento, notadamente sob influência do mandatário do executivo, que sistematicamente desrespeitou as recomendações sanitárias.

Em contrapartida, algumas pessoas passaram a adotar comportamentos mais solidários nesse período de pandemia, agindo com a necessária empatia com as necessidades imediatas de proteção e sobrevivência dos segmentos desprovidos de recursos materiais. Diante da omissão do Poder Público, foi providenciada a confecção de máscaras de tecido ou com material acrílico para distribuição, sendo que algumas organizações sociais, tais como o Movimento dos Trabalhadores Rurais Sem Terra (MST, 2020), bem como de comunidades de moradores que contam com líderes comunitários que realizam diversas doações de alimentos.

Essas ações solidárias são relevantes e necessárias para tentar reduzir o sofrimento e as dificuldades enfrentadas pelas populações marginalizadas por diversas razões históricas, políticas, sociais e econômicas. Denotam, outrossim, um caráter de reconhecimento do outro como um eu, em que aquele que possui alguma condição mais privilegiada procura meios de colaboração para que o outro possa ter acesso aos meios de sobrevivência fundamentais à manutenção da sua dignidade.

Essas ações, por melhores que sejam e reflitam um aspecto da fraternidade no âmbito da solidariedade social, deixam à margem a necessária discussão a respeito do modo de produção capitalista, bem como a sua (in)compatibilidade com o compromisso de concretização dos princípios da liberdade, igualdade e fraternidade cunhados pela Revolução Francesa. A pandemia provocada pelo coronavírus (COVID-19), interferindo diretamente na rotina cotidiana em todo o mundo, e levando à desaceleração da produção e do consumo supérfluo, torna-se também uma oportunidade na história da humanidade para, diante dessa crise sanitária, avaliar o mundo que se pretende construir no pós-pandemia. Quais os valores e os aprendizados que a humanidade é capaz de extrair desse momento delicado em que todos enfrentamos? Como destaca Alysson Mascaro (2020), a atual crise é estrutural tanto na economia como na política e na sociabilidade, abrindo possibilidades históricas de repensar o modo de vida. 
Como bem analisado por João Ricardo Dornelles (2020, p. 94-96) o fím último do capitalismo é a acumulação ampliada e a reprodução permanente do próprio capital. Por isso, também é fundamental para o enfrentamento da pandemia, a contenção de interesses privados de determinados grupos econômicos, através da presença de um Estado comprometido e responsável com a questão social, realizando políticas públicas e investindo em setores essenciais como saúde e educação públicas, pesquisa e saneamento básico. Ainda, que implemente políticas de manutenção de empregos e de uma renda mínima para desempregados e pessoas de baixa renda, promovendo ações para atendimento aos moradores em situação de rua, bem como enfrentamento de questões econômicas fundamentais, tais como a taxação de grandes fortunas. Estas demandas promovem, além de uma melhor redistribuição de riquezas e redução das desigualdades sociais, o espírito de solidariedade social com a população economicamente pobre.

Desditosamente, o contexto político e econômico nacional está na contramão da promoção de um espírito de fraternidade entre os cidadãos, empresários e entidades públicas. A fraternidade não se consubstancia em tônica de governo, manifestando-se em ações isoladas de determinados indivíduos e grupos sociais, os quais se solidarizam com as condições precárias de uma parcela considerável dos brasileiros. Ainda assim, cabe a coletividade construir os caminhos pós-pandemia, para que se consiga galgar na construção de uma sociabilidade materialmente fraterna.

\section{Considerações finais}

Um dos questionamentos mais prosaicos afeito ao contexto de pandemia da COVID-19 é quando a rotina de normalidade retornará. Caso se adote uma perspectiva otimista, o que se espera é que jamais regresse. A pandemia pode servir como ponto de inflexão no sentido de que se corrija o percurso de uma vida cotidiana marcada pelo individualismo, tracejado como mecanismo central de prover a sobrevivência material, em que a competição se transmutou em regra inquestionável da sociabilidade.

É preciso valer desse tempo para questionar o mundo que queremos construir e viver após a pandemia. Para que a fraternidade possa ser concretizada, é preciso lutar por um mundo que não naturalize as desigualdades materiais existentes e decorrentes do modo de produção capitalista, bem como que valorize e acredite no ser humano como um ser capaz de conviver em harmonia, com o indispensável para a sua sobrevivência e para o pleno desenvolvimento de sua capacidade. 
Como dito na afamada Tese III de Walter Benjamin (2014, p. 242): "somente a humanidade redimida obterá o seu passado completo. Isso quer dizer: somente para a humanidade redimida o seu passado tornou-se citável, em cada um dos seus momentos". Lamentavelmente, muitas pessoas já morreram e muitas não sobreviverão a pandemia, o que torna o nosso dever e o compromisso com a humanidade ainda maior, em memória de todos aqueles que não terão a chance de reconstruir esse novo mundo que buscamos mais livre, igualitário e fraterno.

\section{REFERÊNCIAS}

AGAMBEN, Giorgio. Reflexões sobre a Peste: ensaios em tempo de pandemia. São Paulo: Boitempo, 2020.

BAGGIO, Antônio Maria (ORG.). O Princípio Esquecido /1: a fraternidade na reflexão atual das ciências políticas. Vargem Grande Paulista: Cidade Nova, 2008.

BELLO, Enzo. A Cidadania e a Luta Política dos Movimentos Sociais Urbanos. Caxias do Sul: Educs, 2013.

BENJAMIN, Walter. Magia e Técnica, Arte e Política: ensaios sobre literatura e história da cultura. Obras Escolhidas I. 8. ed. São Paulo: Brasiliense, 2014.

DARDOT, Pierre; LAVAL, Christian. A Nova Razão do Mundo: ensaio sobre a sociedade neoliberal. São Paulo: Boitempo, 2016.

DORNELLES, João Ricardo. Necrocapitalismo e Neofascismo em Tempos de Peste. In: AGUSTO; Cristiane Brandão; SANTOS, Rogerio Dultra dos. Pandemias e Pandemônio no Brasil. São Paulo: Tirant lo Blanch, 2020.

HEGEL, Georg Wilhelm Friedrich. Filosofia da História. 2. ed. Brasília: UNB, 1999.

HOBSBAWN, Eric. A Era das Revoluções (1789-1848). 38. ed. Rio de Janeiro: Paz e Terra, 2017.

HONNETH, Axel. A Ideia de Socialismo. Lisboa: Edições 70, 2017.

HORKHEIMER, Max. Teoria Tradicional e Teoria Crítica. Textos Escolhidos (Os

Pensadores). In: HORKHEIMER, Max; ADORNO, Theodor. 5. ed. São Paulo: Nova Cultural, 1991.

LYRA FILHO, Roberto. O que é direito. 20a ed. São Paulo: Brasiliense, 2000.

MARCUSE, Herbert. Razão e Revolução. Rio de Janeiro: Paz e Terra, 1978.

MARX, Karl. Crítica ao Programa de Gotha. In: MARK, Karl; ENGELS, Friedrich. Obras Escolhidas. Moscou/Lisboa: Progresso/ Avante, 1985. 
MARX, KARL. Die Junirevolution (A Revolução de Junho) - 29 de Junho de 1848.

Disponível em: http://www.scientific-socialism.de/KMFEDireitoCAP20Port.htm. Acesso em 30 de jun. 2020.

MARX, Karl. Sobre a Questão Judaica. São Paulo: Boitempo, 2010.

MASCARO, Alysson Leandro. Crise e Pandemia. São Paulo: Boitempo, 2020.

MST - MOVIMENTO DOS TRABALHADORES RURAIS SEM TERRA (2020). MST.

Disponível em $<$ https://mst.org.br/2020/06/04/mst-lanca-plano-emergencial-com-doacao-de10-toneladas-de-alimentos-nesta-sexta-feira-05-no-parana/ $>\mathrm{e}$

$<$ https://gazetaweb.globo.com/portal/noticia/2020/04/_103168.php>. Acesso em 28 de jun. 2020 .

OMS - ORGANIZAÇÃO MUNDIAL DA SAÚDE (2020). OMS. Disponível em $<$ https://www.who.int/docs/default-source/coronaviruse/situation-reports/20200626-covid-19sitrep-158.pdf?sfvrsn=1d1aae8a_2\&ua=1 $>$ e $<$ https://www.sul21.com.br/ultimasnoticias/coronavirus/2020/06/brasil-registra-os-piores-cenarios-da-covid-19-no-mundo-etransmissao-volta-a-crescer/>. Acesso em 28 de jun. 2020.

OPAN - ORGANIZAÇÃO PAN-AMERICANA DE SAÚDE (2020). OPAN. Disponível em: ttps://www.paho.org/bra/index.php?option=com_content\&view $=$ article\&id=6101: covid19\&It emid=875> . Acesso em 27 de jun. 2020.

ROPELATO, Daniela. Notas sobre Participação e Fraternidade. In: BAGGIO, Antônio Maria (ORG.). O Princípio Esquecido /1: a fraternidade na reflexão atual das ciências políticas. Vargem Grande Paulista: Cidade Nova, 2008.

SANDEL, Michael J. Justiça: o que é fazer a coisa certa. 24. ed. Rio de Janeiro: Civilização Brasileira, 2017.

TOSI, Giuseppe. Religião e Política: três possíveis relações. Revista Religare, ISSN: 19826605, v.15, n.2, dezembro de 2018.

WEBER, Thadeu. Ética e Filosofia do Direito: autonomia e dignidade da pessoa humana. Petrópolis: Vozes, 2013.

ŽIŽEK, Slavoj. Pandemia: covid-19 e a reinvenção do comunismo. São Paulo: Boitempo, 2020. 